\title{
Surface Studies on HgCdTe Using Non-aqueous lodine-Based Polishing Solution
}

\author{
RADHESHYAM NOKHWAL, ${ }^{1,2}$ VANYA SRIVASTAV ${ }^{10},{ }^{1,3}$ ANSHU GOYAL, ${ }^{1}$ \\ B.L. SHARMA, ${ }^{1}$ S.A. HASHMI, ${ }^{2}$ and R.K. SHARMA ${ }^{1}$
}

1.-Solid State Physics Laboratory, Lucknow Road, Timarpur, Delhi, India. 2.-Department of Physics, University of Delhi, Delhi, India. 3.—e-mail: vanya.srivastav@gmail.com

\begin{abstract}
Bromine- and iodine-based solutions were compared for surface preparation of $\mathrm{HgCdTe}$ epilayers. The iodine (I)-potassium iodide (KI)-based non-aqueous solution for surface preparation of mercury cadmium telluride $(\mathrm{HgCdTe})$ epilayers is less corrosive, less toxic and technologically more suitable compared to the widely used bromine-based etchants. It provides improved surface morphology and a lower amount of oxides. A comparative study of the oxide content and elemental tellurium residue on the polished surface was made by x-ray photoelectron spectrometry measurements. Least elemental Te content was observed on the HgCdTe surface polished with I-KI solution as compared to bromine-based etchants. It may result in reduced trap density at the surface of $\mathrm{HgCdTe}$. The possibility of potassium diffusion due to I-KI polishing at the $\mathrm{HgCdTe}$ surface, as well as at the cadmium zinc telluride (CdZnTe)-HgCdTe interface, has been ruled out using secondary ion mass spectrometry. Performance of photodiodes fabricated on the polished epilayers $\left(\mathrm{Hg}_{0.7} \mathrm{Cd}_{0.3} \mathrm{Te}\right)$ was assessed and the zero bias dynamic resistance area product $\left(\mathrm{R}_{0} \mathrm{~A}\right)$ was measured as $>5 \times 10^{4} \Omega \mathrm{cm}^{2}$ under stray illumination.
\end{abstract}

Key words: $\mathrm{HgCdTe}, \mathrm{HgCdTe}$ oxides, roughness, surface morphology, XPS

\section{INTRODUCTION}

Mercury cadmium telluride (MCT) is a tunable band gap semiconductor which covers the entire infrared (IR) wavelength range, and the compound is extensively used for fabrication of third-generation IR focal plane arrays. ${ }^{1}$ Fabrication of highquality IR detectors demands uniformity of the material in terms of composition, low defect density and good surface quality. The as-grown $\mathrm{HgCdTe}$ epilayers have several types of defects, such as micro-twins, dislocations, hillocks and voids. Additionally, there is a thin defective, low composition $(x)$ layer on the top surface that persists after annealing for reasons reported elsewhere. ${ }^{2,3}$ It is essential to remove these defects prior to device fabrication, making surface preparation a key process in the fabrication of $\mathrm{HgCdTe}$ photovoltaic

(Received July 27, 2016; accepted August 28, 2017;

published online September 11, 2017) arrays. The common method is mechanical polishing using alumina powder followed by chemo-mechanical polishing and chemical-free etching, since the mechanical polishing procedure leaves the $\mathrm{HgCdTe}$ surface mechanically damaged to a depth of $\sim 1-2 \mu \mathrm{m}$. Of a variety of chemical solutions reported for chemo-mechanical polishing of $\mathrm{HgCdTe}$ epilayers, ${ }^{4-8}$ bromine-based chemical solutions are used widely for post-polishing surface treatment. However, the etch rate of bromine-methanol is rapid and removes material very quickly even in dilute solutions. Thus, this method leaves a rough and non-stoichiometric surface., ${ }^{9,10}$ After etching, the bromine-methanol solution produces a Te-rich surface because of different bond energies between $\mathrm{Te}-\mathrm{Cd}$ and Te-Hg. This is followed by the creation of a few Angstroms of Ta e oxide layer on the surface due to air exposure that, in turn, degrades the interface between the $\mathrm{HgCdTe}$ surface and its passivant cadmium telluride (CdTe). ${ }^{9}$ It increases the interface trap density and results in a high 
surface recombination velocity (SRV) of minority carriers thus degrading the zero bias dynamic resistance of diodes by increase of dark current. ${ }^{9,10}$ There is a need to control the mechanical damage and surface stoichiometry of polished $\mathrm{HgCdTe}$ wafers to reduce SRV due to defects.

In this paper, we explore the possibility of using iodine-based solutions for surface preparation of $\mathrm{HgCdTe}$ epilayers. In recent years, iodine-based solutions have been reported for the surface preparation of CdZnTe substrates. ${ }^{11,12}$ We propose an iodine-, potassium iodide-, and ethylene glycolbased chemo-mechanical polishing solution for HgCdTe epilayers. The main advantage of this solution is its considerable polishing ability with a low etch rate in comparison to other bromine-based solutions and a better surface stoichiometry required for passivation of surface. Additionally, being less corrosive, less toxic, economical, easy to prepare and simple cleaning procedure of the etched samples are other advantages of this solution. The various results of polishing with iodine-based solution are discussed. Surface morphology of the polished epilayers along with the roughness data are presented. The quantitative evaluation of oxides and elemental Te on the surface of $\mathrm{HgCdTe}$ was carried out by x-ray photoelectron spectrometry (XPS) for the three different solutions. The possibility of potassium diffusion in the upper surface of the $\mathrm{HgCdTe}$, as well as at the $\mathrm{HgCdTe} /$ CdZnTe interface, was studied by secondary ion mass spectrometry (SIMS). The effect of iodine polishing on the performance of the fabricated photodiodes is also presented.

\section{EXPERIMENTAL}

The HgCdTe epilayers used in this study were grown by vertical dipping liquid phase epitaxy on the lattice-matched CdZnTe substrate. The dislocation density of these samples was fixed at $<1 \times$ $10^{5} \mathrm{~cm}^{-2}$ by separately revealing the etch pit density in the modified Chen etchant. ${ }^{13}$ Low defect density is essential to study the effect of surface treatment on device performance. The as-grown epilayers were cut with a wire saw machine in $5 \times 5 \mathrm{~mm}^{2}$ pieces. After cutting, these samples were chemically polished by the following three solutions: (1) Sol-A: bromine-methanol (1\% $\mathrm{Br}_{2}$ : $\left.\mathrm{CH}_{3} \mathrm{OH}\right) ;{ }^{9}, 10,14$ (2) Sol-B: bromine-hydrogen bromide in acetic acid $\left(2 \% \mathrm{Br}_{2}\right.$ : $\mathrm{HBr}$-glacial acetic acid) ${ }^{5}$ and (3) Sol-C: iodine-potassium iodide $\left(\mathrm{I}_{2}: \mathrm{KI}_{2} \mathrm{C}_{2} \mathrm{H}_{6} \mathrm{O}_{2}\right):(1 \mathrm{~g}: 4 \mathrm{~g}: 10 \mathrm{ml})+\mathrm{KOH}$. Solutions A and $\mathrm{B}$ are well-known standard etchants for $\mathrm{HgCdTe}$ and were prepared in the compositions mentioned above.

Iodine and potassium iodide in water is a wellknown gold etchant. ${ }^{15}$ Initially, we used this solution for the surface preparation of HgCdTe, but the surface became oxidized and then hazy after polishing with gold etchant. Therefore, we

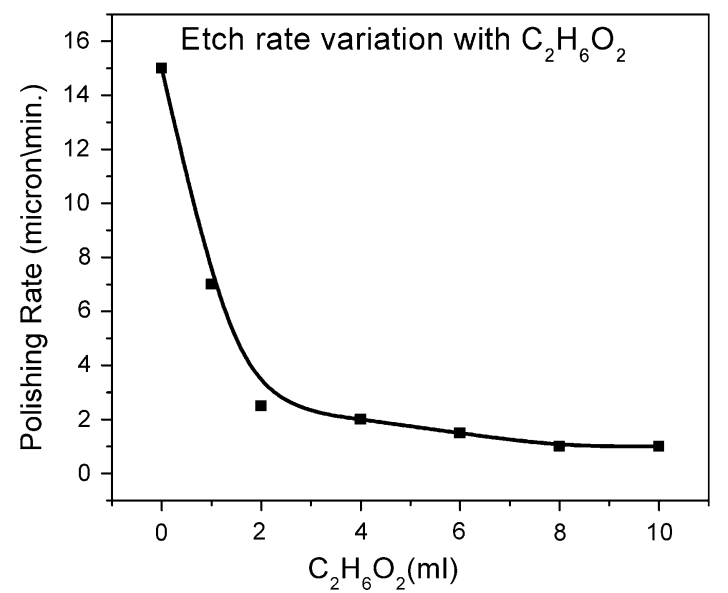

Fig. 1. Polishing rate of $\mathrm{HgCdTe}$ in the mother solution as a function of ethylene glycol concentration.

experimented with this solution and made a different polishing solution (Sol-C). This solution is prepared by mixing iodine, potassium iodide (KI) and ethylene glycol $\left(\mathrm{C}_{2} \mathrm{H}_{6} \mathrm{O}_{2}\right)$ in the ratio of [1 g:4 g:10 ml]. Hereafter, this composition is referred to as the mother solution (MS). The MS can be further diluted with ethylene glycol according to the required removal rate of $\mathrm{HgCdTe}$, as shown in Fig. 1. The functionality of $\mathrm{C}_{2} \mathrm{H}_{6} \mathrm{O}_{2}$ in the Sol-C is to decrease the etch rate and to reduce the possibility of oxide formation on the surface of the sample, since the water content of the solution is nil. This solution is natively acidic in nature. We added a few drops of $\mathrm{KOH}$ solution to make it basic. $\mathrm{KOH}$ is usually used to reduce the hillock density at the semiconductor material surface. ${ }^{16,17} \mathrm{KOH}$ is highly basic ( $\mathrm{pH} \sim 12$ ) and it dissolves easily in water. It was found after many in-house experiments that a slightly basic solution provides optimal surface morphology. After chemo-mechanical polishing with chemical solution Sol-C, the samples were cleaned in de-ionized water and dried in high-purity nitrogen gas. The conventional etchant, Sol-A, produces edge rounding in the sample because of its free etching reaction. On the other hand, this problem was not observed with Sol-C because there is no free etching reaction in this solution, as is clearly shown in Fig. $2 a$ and b. Figure 2a depicts edge rounding in the $\mathrm{HgCdTe}$ sample polished with Sol-A. CdZnTe is revealed at the edges because of the purely chemical etching taking place at the corners of the sample. Figure $2 b$ does not show any edge rounding effect when a similar sample was polished using Sol-C because of the purely mechanical polishing effect. To characterize the polished samples, initially an optical microscope was used for observing the surface morphology. Figure $3 \mathrm{a}$ and $\mathrm{b}$ depicts the morphology of the as-grown HgCdTe epilayer and polished epilayer, respectively.

The XPS spectra were recorded with an Omicron Spectrometer, which has a monochromatic $\mathrm{Al} \mathrm{K} \alpha$ 

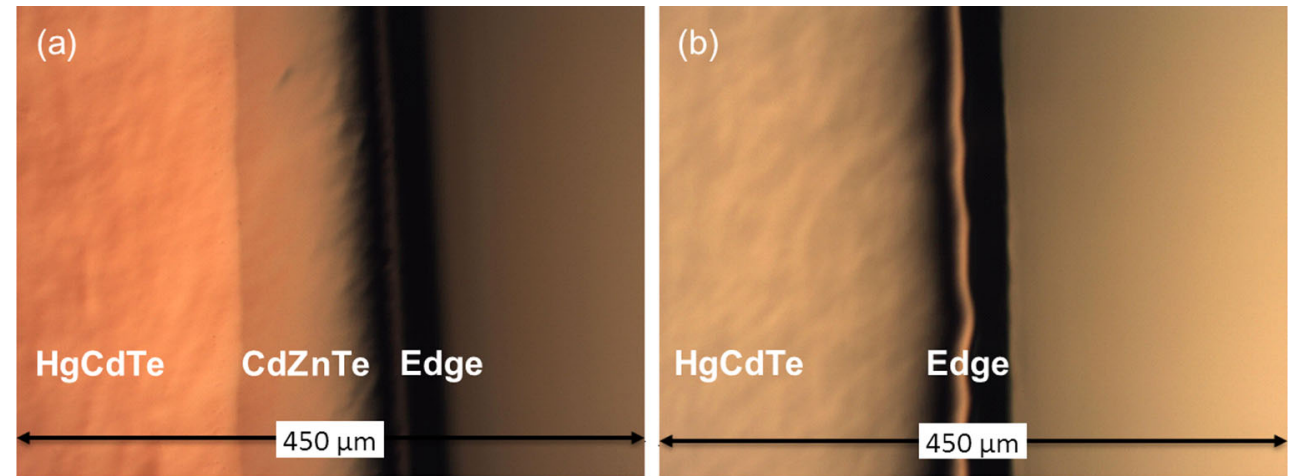

Fig. 2. CdZnTe substrate shows edge rounding in sample (a) after polishing in Sol-A; and no edge rounding in sample (b) after polishing with Sol-C.
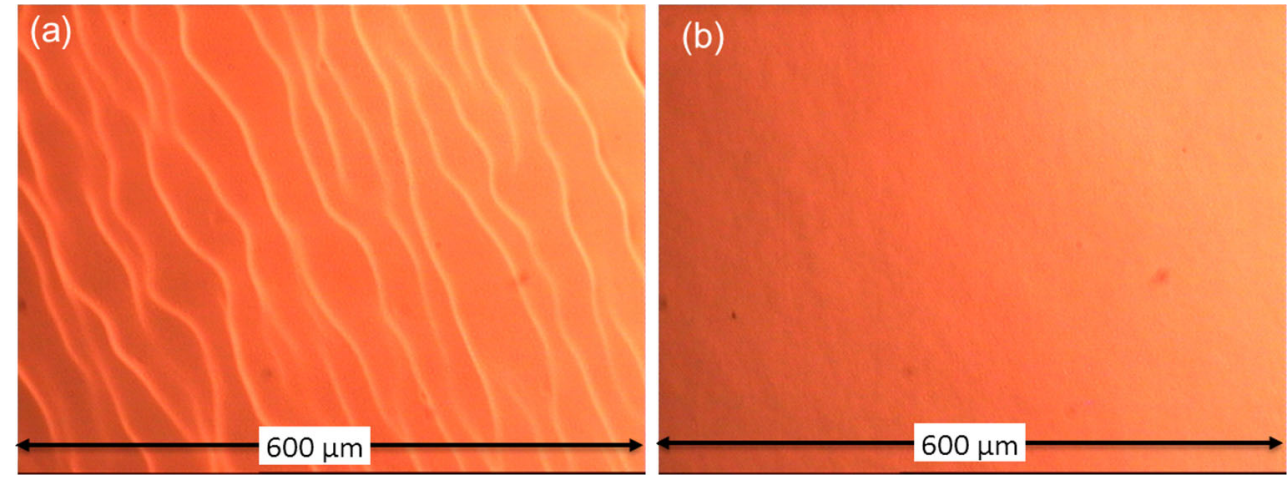

Fig. 3. Surface morphology of the as grown HgCdTe LPE epilayer (a) and surface morphology of this epilayer after chemo-mechanical polishing with solution Sol-C (b).

source and a hemispherical analyzer working at a constant pass energy of $50 \mathrm{eV}$ for core-level spectra, and the analyzed area was less than $2 \mathrm{~mm}$ in diameter. The corresponding energy resolution was of the orderof $0.6 \mathrm{eV}$ for the strongest spectra. In every measurement, binding energy (BE) scale was calibrated using adventitious carbon at $285 \mathrm{eV}$. The polished samples were promptly loaded in the vacuum chamber of XPS system. The possibility of potassium diffusion into the polished surface was studied by CAMECA IMS 7F SIMS. An $\mathrm{O}_{2}^{+}$primary ion beam with impact energy of $5 \mathrm{keV}$ and a current of approximately $100 \mathrm{nA}$ was used to raster $250 \times 250 \mu \mathrm{m}^{2}$ of the sample surface.

The polished epilayer was then used to fabricate a photodiode array with diode area $50 \times 50 \mu \mathrm{m}^{2}$. This fabrication involves the creation of $\mathrm{Hg}_{0.7} \mathrm{Cd}_{0.3} \mathrm{Te}$ diodes in the $n^{+}-p$ homojunction configuration by boron ion implantation through a thick CdTe passivation layer. Dark current-voltage $(I-V)$ characteristics of some of these diodes were measured at $80 \mathrm{~K}$ by probing the individual diodes after mounting the array inside a low temperature cryoprober.

\section{RESULTS AND DISCUSSION}

\section{XPS Analysis}

The survey scan of the HgCdTe surface was recorded and the peaks of $\mathrm{Hg}, \mathrm{Cd}$, Te, along with $\mathrm{O}$ and $\mathrm{C}$, were identified. The presence of $\mathrm{O}$ and $\mathrm{C}$ were expected because, after the cleaning process, it takes a certain amount of time to load the sample into the vacuum chamber of the XPS system. The Te $3 \mathrm{~d}_{5 / 2}$, Cd $3 \mathrm{~d}_{5 / 2}$ and $\mathrm{Hg} 4 \mathrm{f}_{7 / 2}$ peaks were used to analyze the HgCdTe sample surface after treatment with three different chemical solutions, A, B and C. The XPS-resolved peaks of $\mathrm{Te}, \mathrm{Cd}$ and $\mathrm{Hg}$ along with their oxides are shown in Figs. 4, 5, and 6, respectively. Elemental $\mathrm{Te}^{0}$ peaks were separated from the lattice-bound $\mathrm{Te}^{2-}$ peaks using the Gaussian/Lorentzian peak function with a Shirley background. We found that bromine and iodine have different approaches to oxide formation on the HgCdTe surface. Thermodynamically, it has been reported that the chemically etched surface mainly consists of $\mathrm{TeO}_{2}$ with small amounts of $\mathrm{CdTeO}_{3}$ and $\mathrm{HgTeO}_{3}$. $\mathrm{CdTeO}_{3}$ is the most stable oxide according to Gibbs free energy calculations. ${ }^{18}$ Similar oxide 

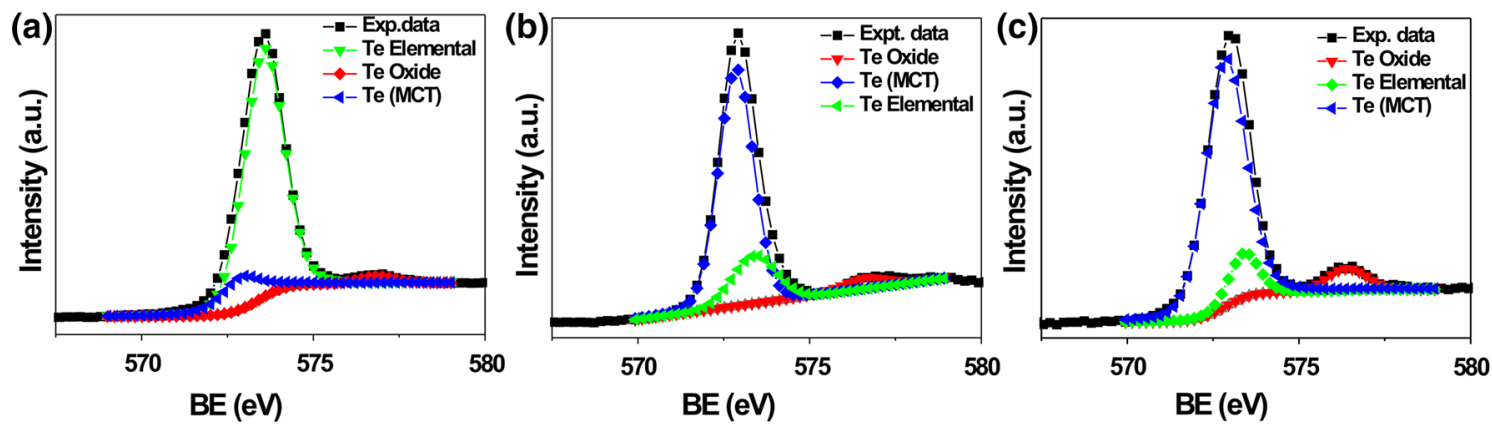

Fig. 4. XPS recorded curves of Te resolved by Gaussian-Lorentzian fitting for the three solutions (a) Sol-A (b) Sol-B, and (c) Sol-C.

peaks were observed in our experimental study with the three different solutions, A, B and C. We discuss the analyzed XPS data in subsequent sections.

\section{Tellurium Oxides}

The Te $3 d_{5 / 2}$ spectrum shows a complex structure in comparison to $\mathrm{Hg} 4 \mathrm{f}_{7 / 2}$ or $\mathrm{Cd} 3 \mathrm{~d}_{5 / 2}$. After polishing with each of these solutions, the $\mathrm{BE}$ of $\mathrm{Te} 3 \mathrm{~d}_{5 / 2}$ peak was estimated and found to be $572 \mathrm{eV}$. The peak was asymmetric and consisted of three peaks obtained by least square peak fitting, as shown in Fig. 4. These peaks were identified after comparing them with published data of $\mathrm{BE}$ values. The first peak of lattice-bound $\mathrm{Te}(\mathrm{HgCdTe})\left(\mathrm{Te}^{2-}\right)$ is at $572.8 \mathrm{eV}$ and the second peak of elemental $\mathrm{Te}\left(\mathrm{Te}^{0}\right)$ is at $573.6 \mathrm{eV}$, as listed in Table I. The third Te oxide peak is also observed at $576.8 \mathrm{eV}$. The nature of Te oxide is somewhat contentious in the literature. $9,10,19$ The exact nature of the oxide could not be determined because of the lack of available $\mathrm{BE}$ values of oxides in the literature. Most researchers have observed an oxide that is comprised of $\mathrm{TeO}_{2} \cdot{ }^{10,11,20}$ According to Rhiger et al., initial oxidation of the prepared $\mathrm{HgCdTe}$ surface produces mostly $\mathrm{TeO}_{2}$ with small amounts of $\mathrm{CdTeO}_{3}$ or $\mathrm{HgTeO}_{3}{ }^{18} \mathrm{~A}$ detailed study by Eggebert et al. suggests that bromine-methanol etching results in elemental $\mathrm{Te}$ and native oxide phases, comprising $\mathrm{HgTe}_{2} \mathrm{O}_{5}$ and $\mathrm{CdTe}_{2} \mathrm{O}_{5}$ at the polished surface of HgCdTe. ${ }^{19}$ The oxide of Te in the form of $\mathrm{TeO}_{2}$ has also been found in the present study, as can be seen from data in Table I. The oxide $\left(\mathrm{TeO}_{2}\right)$ was also confirmed by the $\mathrm{BE}$ difference parameter, $\mathrm{BE}(\mathrm{O} 1 \mathrm{~s})-\mathrm{BE}\left(\mathrm{Te}^{2} \mathrm{~d}_{5 / 2}\right)$, i.e., $\sim 46.0 \mathrm{eV}$, which matches with the literature. ${ }^{20-23}$ The $\mathrm{TeO}_{2}$ can be removed by hydrazine $\left(\mathrm{N}_{2} \mathrm{H}_{4}\right)$ gas treatment ${ }^{10}$ and argon ion sputtering. ${ }^{7}$ It may be inferred from Fig. 7 that Sol-C produces lowest elemental Te and highest lattice bound $\mathrm{Te}(\mathrm{HgCdTe})$ as compared to both Sol-A and Sol-B. It is well known that elemental Te on the surface of HgCdTe produces an unstable surface with $\mathrm{Te}^{0}$ dangling bonds, which in turn results in a high interface trap density. Therefore, Sol-C induces a lower interface trap density and, thus, a more stable interface between passivation and the $\mathrm{HgCdTe}$ surface resulting in better device performance than that achievable with brominebased etchants like Sol-A and Sol-B.

Wet chemical etching or polishing of semiconductor surfaces proceeds according to the well-known oxidation-reduction process. The reactions to form elemental $\mathrm{Te}^{0}$ from lattice-bound $\mathrm{Te}^{2-}$ for all three solutions at the $\mathrm{HgCdTe}$ surface are described here. Bromine from Sol-A or Sol-B is adsorbed on the HgCdTe surface and reacts with lattice Te to release elemental $\mathrm{Te}^{0}$ by the following reaction:

$$
\begin{gathered}
\mathrm{Br}_{2}(\mathrm{aq})+2 \mathrm{e}^{-} \leftrightarrow 2 \mathrm{Br}^{-} \quad \mathrm{E}^{0}=+1.09 \mathrm{~V} \\
\mathrm{Te}(\mathrm{s})+2 \mathrm{e}^{-} \leftrightarrow \mathrm{Te}^{2-} \quad \mathrm{E}^{0}=-1.14 \mathrm{~V}
\end{gathered}
$$

Equation 2 has a tendency to proceed in the opposite direction because of negative electrode potential. The net reaction between bromine and Te from the $\mathrm{HgCdTe}$ surface proceeds as:

$$
\mathrm{Br}_{2}+\mathrm{Te}^{2-}=2 \mathrm{Br}^{-}+\mathrm{Te}^{0} \quad \mathrm{E}^{0}=+2.23 \mathrm{~V}
$$

Elemental Te oxidizes very easily on exposure to air to form $\mathrm{TeO}_{2}{ }^{10}$

$$
\mathrm{Te}^{0}+\mathrm{O}_{2}(\mathrm{~g})=\mathrm{TeO}_{2}
$$

Among the halides, iodine has the lowest electrode potential and the reaction between iodine and telluride proceeds by simple displacement to produce $\mathrm{TeI}_{4}$, which is removed from the surface by polishing. For the iodine-based solution, a similar reaction occurs to leave elemental $\mathrm{Te}^{0}$.

$$
\begin{gathered}
\mathrm{I}_{2}(\mathrm{aq})+2 \mathrm{e}^{-}=2 \mathrm{I}^{-} \quad \mathrm{E}^{0}=+0.54 \mathrm{~V} \\
\mathrm{I}_{2}+\mathrm{Te}^{2-}=\mathrm{Te}^{0}+2 \mathrm{I}^{-} \quad \mathrm{E}^{0}=+1.68 \mathrm{~V}
\end{gathered}
$$

The probability of tellurium bromide formation is very small for Sol-A and Sol-B, while the formation of $\mathrm{TeI}_{4}$ takes place by displacement in the reaction with Sol-C. Therefore, the relative intensity of $\mathrm{Te}^{0}$ is smallest for Sol-C. Thus, we can see from the values of redox potentials for the bromine-tellurium and iodine-tellurium reactions that bromine is a stronger oxidizing agent than iodine. This supports the XPS results that the probability of formation of 
(a)

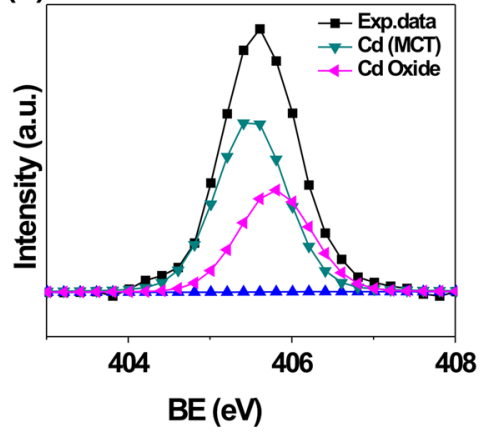

(b)

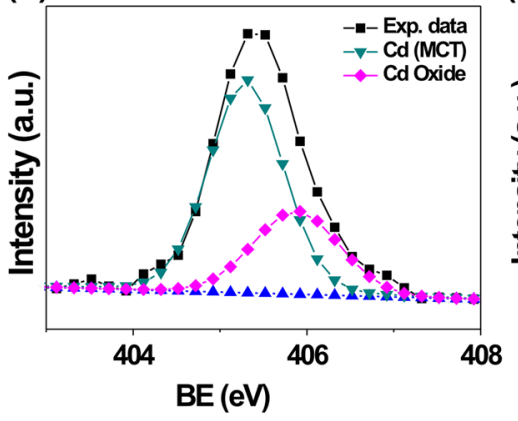

(c)

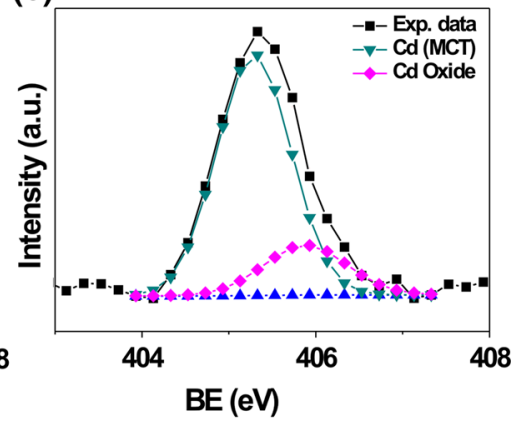

Fig. 5. XPS recorded curves of Cd resolved by Gaussian-Lorentzian fitting for the three solutions (a) Sol-A, (b) Sol-B, and (c) Sol-C.
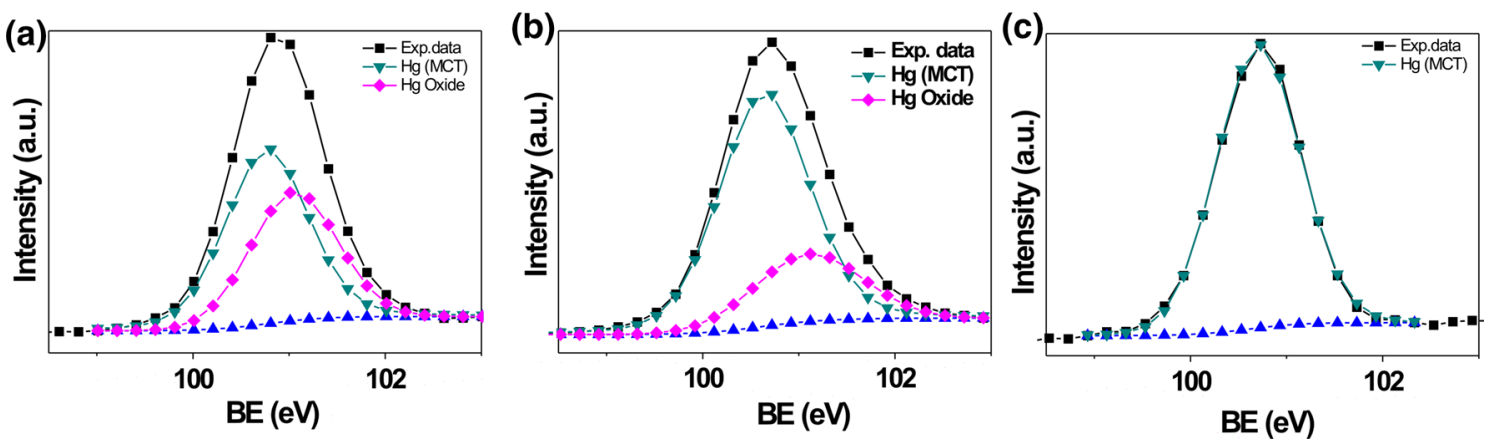

Fig. 6. XPS recorded curves of $\mathrm{Hg}$ resolved by Gaussian-Lorentzian fitting for the three solutions (a) Sol-A, (b) Sol-B, and (c) Sol-C.

elemental Te on the surface of $\mathrm{HgCdTe}$ is higher in the samples treated with bromine-based solutions as compared to iodine-treated solutions.

\section{Cd Oxides}

There were no observed multiple peaks in the $\mathrm{Cd}$ spectrum, which is a sign of negligible oxidation of Cd. But after a long time exposure to air, a small shift in BE was observed by Sporken et al. ${ }^{9}$ Cadmium oxide $\mathrm{CdO}$ and a mixed oxide that is similar to $\mathrm{CdTeO}_{3}$ were found by Varesi et al. ${ }^{24} \mathrm{CdO}$ could not be observed by several other investigators because of inadequate energy resolution of XPS. The presence of Cd oxide on the surface of the HgCdTe in the form of $\mathrm{CdTeO}_{3}$ has also been observed. ${ }^{18,19}$ The oxide $\left(\mathrm{CdTeO}_{3}\right)$ was also confirmed by the $\mathrm{BE}$ difference parameter, $\mathrm{BE}(\mathrm{O} 1 \mathrm{~s})-\mathrm{BE}\left(\mathrm{Cd} 3 \mathrm{~d}_{5 / 2}\right)$, i.e.., $\sim 124.7 .0 \mathrm{eV}$, which matches with the literature. ${ }^{20,25}$ In the present study, the $\mathrm{Cd} 3 \mathrm{~d}_{5 / 2}$ peak was found at $405.5 \mathrm{eV}$, although this peak is also asymmetric, as shown in Fig. 5. This peak was de-convoluted into two peaks by comparing it with the data available in the literature. The first peak shows the $\mathrm{Cd}^{2+} / \mathrm{Cd}$ (HgCdTe) at $405.3 \mathrm{eV}$ and the second peak shows the Cd oxides at $405.8 \mathrm{eV}$. Figure 7 shows that Sol$\mathrm{C}$ produces the highest level of lattice-bound $\mathrm{Cd}$ $\left(\mathrm{Cd}^{2+}\right)$ on the sample surface with a lower level of Cd oxides than that of Sol-A and Sol-B. The chemical reactions for the removal of $\mathrm{Cd}$ from the surface and the formation of Cd oxides, as observed from XPS analysis, can be represented by the following chemical equations:

$$
\begin{gathered}
\mathrm{Br}_{2}+\mathrm{Cd}^{2+}=\mathrm{CdBr}_{2} \\
\mathrm{I}_{2}+\mathrm{Cd}^{2+}=\mathrm{CdI}_{2} \\
\mathrm{Cd}^{2+}+\mathrm{Te}^{2-}=\mathrm{Cd}+\mathrm{Te}^{4+}+4 \mathrm{e}^{-}\left(\mathrm{CdTeO}_{3}\right)
\end{gathered}
$$

\section{Hg Oxides}

$\mathrm{Hg}$ can be oxidized in complex forms, the dominant being $\mathrm{HgTeO}_{3}{ }^{18,19}$ The asymmetric $\mathrm{Hg} 4 \mathrm{f}_{7 / 2}$ peak was found at $100.9 \mathrm{eV}$. In the case of Sol-A and Sol-B, two peaks have been de-convoluted, as shown in Fig. 6. The $\mathrm{Hg}^{2+} / \mathrm{Hg}$ (MCT) peak was observed at $100.7 \mathrm{eV}$ and the $\mathrm{Hg}$ oxide peak was observed at $101.1 \mathrm{eV}$. In contrast, for Sol-C, the $\mathrm{Hg} 4 \mathrm{f}_{7 / 2}$ peak can be considered as a single peak, as shown in Fig. 6. It has been found that different amounts of oxides form when the surface is treated with different solutions. $\mathrm{Hg}$ oxide was found to be negligibly small in the case of Sol-C, whereas it is the highest in the case of Sol-A. Also, $\mathrm{Hg}^{2+}$ is highest with Sol-C and lowest in the case of Sol-A. 


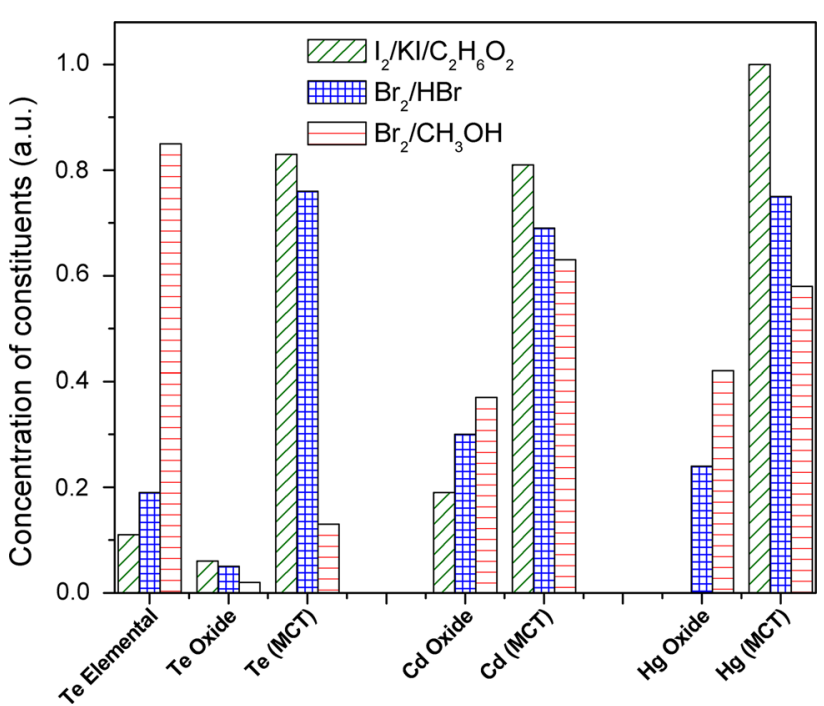

Fig. 7. Comparison of all measured XPS data on the surface of $\mathrm{HgCdTe}$ with three solutions when the total value of a single element was assumed to one on the surface of the sample.

Hence, it is concluded that Sol-C is preferable for the surface preparation of $\mathrm{HgCdTe}$. The chemical reactions described the $\mathrm{Hg}$ removal from the surface, and the formation of $\mathrm{Hg}$ oxides, as observed from XPS analysis, can be represented by the following chemical equations:

$$
\begin{gathered}
\mathrm{Br}_{2}+\mathrm{Hg}^{2+}=\mathrm{HgBr}_{2} \\
\mathrm{I}_{2}+\mathrm{Hg}^{2+}=\mathrm{HgI}_{2} \\
\mathrm{Hg}^{2+}+\mathrm{Te}^{2-}=\mathrm{Hg}+\mathrm{Te}^{4+}+4 \mathrm{e}^{-}\left(\mathrm{HgTeO}_{3}\right)
\end{gathered}
$$

For all three solutions, $\mathrm{Hg}$ and $\mathrm{Cd}$ dissolve as bromides and iodides, while the $\mathrm{Te}, \mathrm{Cd}$ and $\mathrm{Hg}$ oxides are formed in different proportions along with elemental Te. The reactions taking place for the formation of different oxides have been predicted by Rhiger from the quaternary phase equilibrium diagram for the $\mathrm{Hg}-\mathrm{Cd}-\mathrm{Te}-\mathrm{O}$ system $\mathrm{as}^{18}$ :

$$
\begin{gathered}
4 \mathrm{HgTeO}_{3}+2 \mathrm{CdTe}=2 \mathrm{CdTeO}_{3}+3 \mathrm{TeO}_{2}+\mathrm{HgTe}+3 \mathrm{Hg} \\
3 \mathrm{TeO}_{2}+2 \mathrm{CdTe}=2 \mathrm{CdTeO}_{3}+3 \mathrm{Te} \\
\mathrm{Hg}+\mathrm{Te}+(3 / 2) \mathrm{O}_{2}=\mathrm{HgTeO}_{3}
\end{gathered}
$$

Thus, from XPS analyses, it is evident that Sol-C is the best solution for the chemical polishing of the HgCdTe surface because it not only reduces elemental $\mathrm{Te}^{0}$ on the surface but also the quantity of various oxides produced by this solution are lower in comparison to those produced by other two solutions, as shown in Fig. 7.

Surface morphology plays a vital role in determining device performance. Fine control over the defect density is necessary to improve device performance. The morphology and roughness of the 


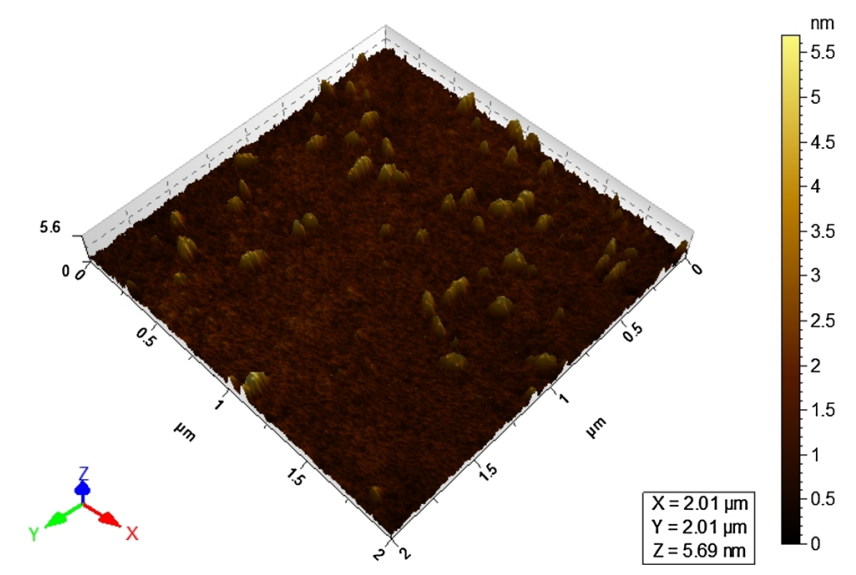

Fig. 8. AFM results showing the surface morphology and average roughness of the layer is $0.55 \mathrm{~nm}$ after chemo-mechanical polishing with solution Sol-C.
HgCdTe surface was measured by atomic force microscopy (AFM) in the tapping mode after surface preparation by Sol-C. Some features are seen over the surface of the polished epilayers which are like a ripple pattern at the nano-scale. The root mean square roughness of the surface, as determined in AFM, is $\sim 0.55 \mathrm{~nm}$ over the area of $2 \times 2 \mu \mathrm{m}^{2}$, as seen in Fig. 8. There are several island-like features having orientations of $1 / 2(111)$ observed in the AFM image. As it appears, these are localized hillocks of tellurium. These hillocks result from the presence of ultra-fine Te precipitates $(\leq 10 \mathrm{~nm})$ in the $\mathrm{HgCdTe}$ material. The surface was observed to be Te-rich from the XPS studies, indicating the presence of elemental Te, which could be due to these hillocks. After polishing with ultra-fine alumina powder, these hillocks were not observed. The characteristic height of these hillocks was $2-3 \mathrm{~nm}$, which depends upon the material removal rate.

\section{SIMS Analysis}

It is well known that the electrical properties of $\mathrm{HgCdTe}$ are governed by the Hg-vacancies and that these can be adjusted after growth by a post-growth treatment like annealing. If background potassium concentration contributes to the carrier concentration of the $\mathrm{HgCdTe}$ epilayer, then it cannot be adjusted by the post-growth treatment. $\mathrm{KI}$ and $\mathrm{KOH}$ are the sources of the $\mathrm{K}$ in Sol-C. It is reported that diffusion of potassium may harm the electrical properties of the material. ${ }^{16}$ Potassium may diffuse during (1) pre-growth surface treatment of CdZnTe, (2) growth of the MCT epilayer and (3) post-growth polishing of the MCT epilayer. The presence of potassium on the surface of $\mathrm{HgCdTe}$ can result in degradation of the passivant-HgCdTe interface by inducing mobile charges in the passivation film. This can lead to deterioration of the electrical properties of the final photodiode. The CdZnTe

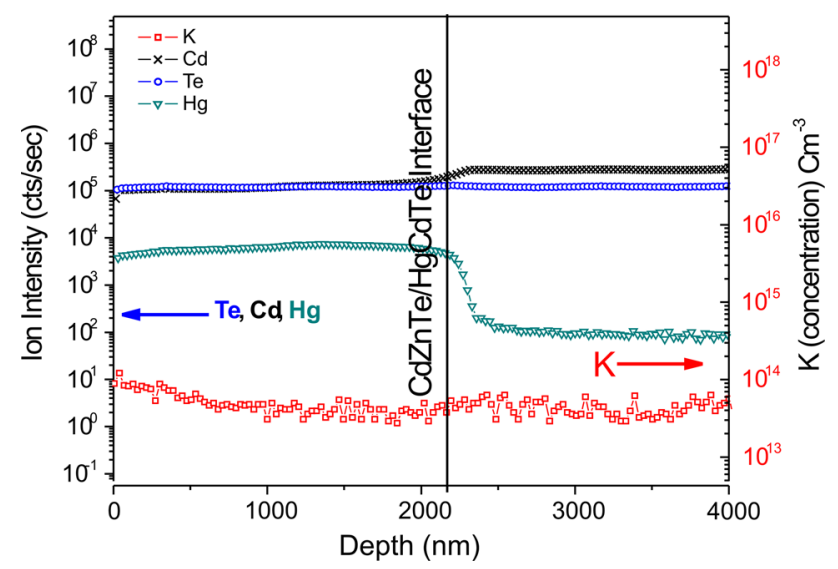

Fig. 9. $\mathrm{K}$ diffusion on the surface of $\mathrm{HgCdTe}$ as well as the $\mathrm{CdZnTe/}$ HgCdTe interface.

substrate was polished by Sol-C and cleaned using $\mathrm{C}_{2} \mathrm{H}_{6} \mathrm{O}_{2}$ followed by rinsing in de-ionized water. The growth of $\mathrm{HgCdTe}$ on $\mathrm{CdZnTe}$ was performed by $\mathrm{LPE}$ at high temperature $\left(\sim 475^{\circ} \mathrm{C}\right)$. Potassium may diffuse into $\mathrm{HgCdTe}$ through the $\mathrm{HgCdTe} / \mathrm{CdZnTe}$ interface during the growth of HgCdTe. ${ }^{16,17}$ After the growth, the as-grown $\mathrm{HgCdTe}$ surface was also polished by Sol-C at room temperature, cleaned using $\mathrm{C}_{2} \mathrm{H}_{6} \mathrm{O}_{2}$ and rinsed in de-ionized water. Here also, a possibility appeared for potassium diffusion into the HgCdTe surface. We tested the potassium diffusion by SIMS and no potassium presence was found either at the surface of $\mathrm{HgCdTe}$ or at the $\mathrm{HgCdTe} / \mathrm{CdZnTe}$ interface, as can be seen from Fig. 9. The mobility of $485 \mathrm{~cm}^{2} \mathrm{~V}^{-1} \mathrm{~s}^{-1}$ and the carrier concentration of $8 \times 10^{15} \mathrm{~cm}^{-3}$ measured at $77 \mathrm{~K}$ by Hall measurements also verified the absence of potassium in these samples. These electrical properties are desirable for the fabrication of mid-wave infrared photodiodes based on $p$-type $\mathrm{HgCdTe}$.

\section{I-V Analysis of Photodiode}

The photodiode array with diode size $50 \times 50 \mu \mathrm{m}^{2}$ was fabricated on the sample chemo-mechanically polished by Sol-C. Dark $I-V$ characteristics of several diodes were measured at $80 \mathrm{~K}$ by probing the individual diodes after mounting the array inside a cryoprober. The cryoprober has a top shutter to view the diodes being probed. There is a provision of Mylar curtains to shield the diode array from stray IR radiation. All these arrangements, although cooled to $80 \mathrm{~K}$, do not completely shield the device from the background. Thus, the nature of probing is such that the diodes become exposed to some background IR radiation during measurements. The measured dark $I-V$ characteristics of one of the representative diodes is shown in Fig. 10. The open circuit voltage of $\sim 100 \mathrm{mV}$ is seen because 


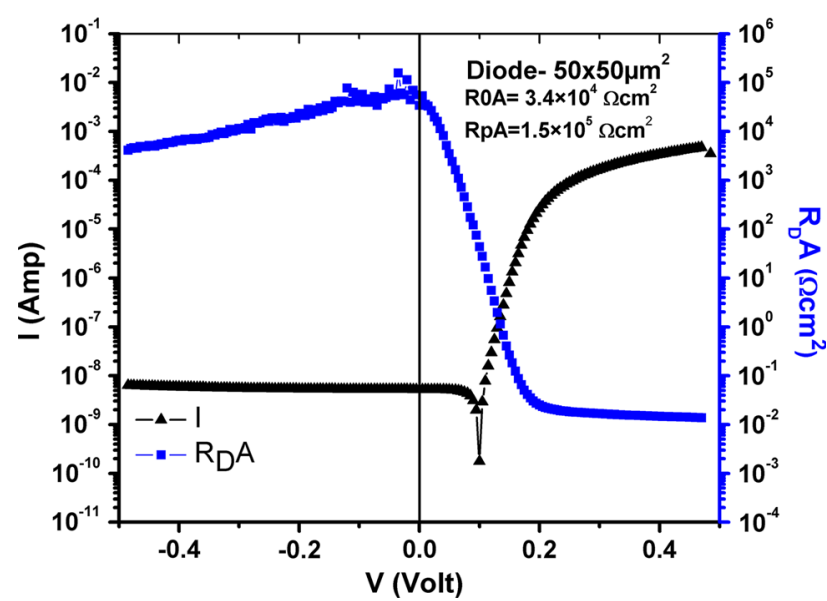

Fig. 10. $I-V$ diagram of a typical photodiode and dynamic resistance area product after chemical polishing with Sol-C.

the diode is exposed to inadvertent background radiation. Under such conditions, the measured dark current density at zero bias is $\sim 2.1 \times 10^{-4} \mathrm{~A} /$ $\mathrm{cm}^{2}$. One of the most important parameters for the photodiode is the $R_{0} A$ product which is governed by conduction mechanisms like generation recombination (g-r), diffusion and shunt. ${ }^{26}$ The $\mathrm{R}_{0} \mathrm{~A}$ product was measured to be $\sim 3.4 \times 10^{4} \Omega \mathrm{cm}^{2}$ under open shutter conditions for several pixels. Another important parameter of a photodiode is the peak dynamic resistance area product ( $\mathrm{RpA})$, which is important for improving the injection efficiency of the device. The RpA product for the diode was $1.5 \times 10^{5} \Omega \mathrm{cm}^{2}$ at $\sim 35-50 \mathrm{mV}$ reverse bias. These values are expected to improve by more than an order of magnitude under complete dark conditions.

It is well known that surface treatment significantly affects the SRV which is induced by g-r centers. The presence of surface states gives rise to a space-charge layer near the surface. Surface defects and surface roughness result in the generation of surface traps with a uniform density in the forbidden gap of the material. ${ }^{27}$ These traps act as recombination centers on semiconductor surfaces with energy levels in the forbidden gap. These traps increase the SRV, resulting in high dark current values. ${ }^{28}$ It is evident from the measured $I-V$ characteristics that surface treatment by polishing with solution Sol-C gives low g-r centers because the reverse current is almost constant as a function of bias. Similar results were observed for many individual diodes on the sample. Thus, it can be concluded that the surface preparation of $\mathrm{HgCdTe}$ epitaxial layers by the proposed iodine-based solution is capable of giving a good performance in the fabricated devices. These are encouraging results for the incorporation of iodine-based polishing of the HgCdTe surface in device processing. We have successfully incorporated a Sol-C-based polishing process in the final device fabrication sequence, and many good IR devices have been made using this process.

\section{CONCLUSIONS}

We proposed a non-aqueous slow-polishing solution $\left(\mathrm{I}_{2}: \mathrm{KI}: \mathrm{C}_{2} \mathrm{H}_{6} \mathrm{O}_{2}: \quad(1 \mathrm{~g}: 4 \mathrm{~g}: 10 \mathrm{ml})+\mathrm{KOH}\right)$ and investigated its potential for the surface treatment of $\mathrm{HgCdTe}$ epilayers to be used for the fabrication of high-quality devices. The surface stoichiometry and morphology of epilayers polished using this solution were found to be improved as compared to those polished with the conventional bromine-based etching solutions. The XPS analyses shows that the iodine-based solution results in lower $\mathrm{Te}^{0}$ content on the surface than bromine-based solutions. The oxides of $\mathrm{Te}, \mathrm{Cd}$ and $\mathrm{Hg}$ were present on the surface of the epilayers in the form of $\mathrm{TeO}_{2}, \mathrm{CdTeO}_{3}$ and $\mathrm{HgTeO}_{3}$, respectively, and the oxides were at minimum levels for the proposed solution. Furthermore, the roughness of these epilayers was around $0.5 \mathrm{~nm}$ with an improved surface morphology. The possibility of potassium diffusion within the epilayer and at its interface with the substrate has been investigated using SIMS measurements, and it was confirmed that there was no such diffusion. The $I-V$ characteristics exhibited g-r dominance with $\mathrm{R}_{0} \mathrm{~A}$ and RpA being $\sim 3.4 \times 10^{4} \Omega \mathrm{cm}^{2}$ and $1.5 \times 10^{5} \Omega \mathrm{cm}^{2}$, respectively, which is indicative of good performance. On account of these observations, it can be concluded that the surface preparation of $\mathrm{HgCdTe}$ by the proposed iodine-based solution is a better alternative to the conventional etching process in bromine-based solutions for the surface treatment of $\mathrm{HgCdTe}$ wafers.

\section{ACKNOWLEDGEMENTS}

The authors are grateful to Dr. Ashok Kapoor, Mr. Akhilesh Pandey and Dr. Brajesh Singh Yadav for using the characterization tool. Authors are also thankful to Dr. R.S. Saxena and Mr. Varun Sharma for their helpful discussion in analysis of various results.

\section{REFERENCES}

1. A. Rogalski, Opto Electron. Rev. 20, 279 (2012).

2. A.J. Stoltz, J.D. Benson, M. Jaime-Vasquez, P.J. Smith, L.A. Almeida, R. Jacobs, J. Markunas, K. Brogden, A. Brown, C. Lennon, P. Maloney, and N. Supola, J. Electron. Mater. 43, 3708 (2014).

3. R. Nokhwal, A. Pandey, B. L. Sharma, P. Sharma, P. Garg, S. A. Hashmi, and R. K. Sharma, Environmental Science and Engineering, p. 829 (Springer International Publishing, Cham, 2013).

4. V.G. Kesler and E.R. Zakirov, Int. Conf. Young Spec. Micro/Nanotechnol. Electron. Dev. EDM 2, 33 (2014).

5. V. Srivastav, R. Pal, and H.P. Vyas, Opto Electron. Rev. 13, 197 (2005).

6. B.H. Erné, F. Lefèvre, D. Lorans, D. Ballutaud, C. Debiemme-Chouvy, J. Vigneron, and A. Etcheberry, Appl. Surf. Sci. 175-176, 579 (2001).

7. P.W. Leech, P.J. Gwynn, and M.H. Kibel, Appl. Surf. Sci. 37, 291 (1989).

8. W.J. Danaher, L.E. Lyons, M. Marychurch, and G.C. Morris, Appl. Surf. Sci. 27, 338 (1986).

9. R. Sporken, R. Kiran, T. Casselman, F. Aqariden, S. Velicu, Y. Chang, and S. Sivananthan, J. Electron. Mater. 38, 1781 (2009). 
10. M.Y. Lee, Y.S. Lee, and H.C. Lee, Appl. Phys. Lett. 88, 204101-204111 (2006).

11. P. Moravec, Z.F. Tomashik, V.G. Ivanits'Ka, V.M. Tomashik, J. Franc, K. Mašek, and P. Höschl, J. Electron. Mater. 41, 2838 (2012).

12. F. Aqariden, S. Tari, K. Nissanka, J. Li, N. Kioussis, R.E. Pimpinella, and M. Dobrowolska, J. Electron. Mater. 41, 2893 (2012).

13. R. Nokhwal, R.S. Saxena, B.L. Sharma, A. Kumar, S.A. Hashmi, and R.K. Sharma, Infrared Phys. Technol. 71, 378 (2015)

14. W.H. Chang, T. Lee, and W.M. Lau, J. Appl. Phys. 68, 4816 (1990).

15. P. Alto, P.P. Data, D. Joshua, R. Cited, C. Cochran, A.J. Fusco, and E. Al., "United States Patent," 4600469, 2005.

16. J.S. Kim, Y.H. Kim, B.K. Kim, and H.J. Je, Solid State Electron. 48, 1623 (2004).

17. J. Giess, J.E. Hails, A. Graham, G. Blackmore, M.R. Houlton, J. Newey, M.L. Young, M.G. Astles, W. Bell, and D.J. Cole-Hamilton, J. Electron. Mater. 24, 1149 (1995).

18. D.R. Rhiger and R.E. Kvaas, J. Vac. Sci. Technol. A Vac. Surf. Film 1, 1712 (1983).
19. M. Seelmann-Eggebert, G. Brandt, and H.J. Richter, J. Vac. Sci. Technol. A Vac. Surf. Film 2, 11 (1984).

20. A. B. Christie, I. Sutherland, and J. M. Walls, Surf. Sci. 135, 225 (1983).

21. A.J. Ricco, J. Vac. Sci. Technol. A Vac. Surf. Film 2, 910 (1984).

22. B.V.R. Chowdari and P. Pramoda Kumari, J. Non Cryst. Solids 197, 31 (1996).

23. F. Garbassi, J.C.J. Bart, and G. Petrini, J. Electron. Spectros. Relat. Phenom. 22, 95 (1981).

24. J.B. Varesi, J.D. Benson, M. Jaime-Vasquez, M. Martinka, A.J. Stoltz, and J.H. Dinan, J. Electron. Mater. 35, 1443 (2006).

25. J.S. Hammond, S.W. Gaarenstroom, and N. Winograd, Anal. Chem. 47, 2193 (1975)

26. R.S. Saxena, R. Nokhwal, R.K. Bhan, and R.K. Sharma, Infrared Phys. Technol. 56, 69 (2013).

27. E. Finkman, J. Vac. Sci. Technol. A Vac. Surf. Film 7, 464 (1989).

28. P. Madejczyk, A. Piotrowski, K. Kłos, W. Gawron, A. Rogalski, J. Rutkowski, and W. Mróz, Bull. Polish Acad. Sci. Tech. Sci. 57, 139 (2010). 